Covered in: Web of Science (WOS); EBSCO; ERIH+; Google Scholar; Index Copernicus; Ideas RePeC; Econpapers; Socionet; CEEOL; Ulrich ProQuest; Cabell, Journalseek; Scipio; Philpapers; SHERPA/RoMEO repositories; KVK; WorldCat; CrossRef; CrossCheck

2020, Volume 11, Issue 3, pages: 318-331 | https://doi.org/10.18662/po/11.3/217

\section{Subjectivity of Wersten Personality: Limits of Rationality}

\section{Olga POROSHENKO ${ }^{1}$}

${ }^{1} \mathrm{PhD}$ in social philosophy, associate professor, Department of History and Philosophy, Head for International Relations, Kazan State University of Architecture and Engineering, olgaporo@mail.ru
Abstract: If we don't go deep into scientific definitions and interpretations, then such words as "Self", "Subjectivity", "Internal World" appear to be the same. At least, they all stand for something inside the human, inside the intimate spiritual world that is hidden from curious eyes.

That all would be fine and even congruent with us, only that internal world was not so fragile. What terrible tragedies do we experience when confronted in minor internal conflicts with others arising from "misunderstanding", "noninclusion", not to mention life tragedies, such as, "solitude" and "self-destruction".

So, western personas, you and I, face an insolvable contradiction: we want to create, as we are subjects, but postmodernists forbid us. Since it is forbidden to change the external world, there is only one choice: to refute the external world and turn your gaze into yourself.

If we freed our mind from pragmatic chains, we would clearly see that sociological problem of self-identification is a more fundamental problem; it is a problem of selfjustification of "my I", i.e. a problem of my personal anthropodicity.

Oriental metaphysics is impenetrable to the West. The entire "esoteric" line of European philosophy from Plato to Heidegger can be called the "technique of translating" oriental metaphysics into the language of European science. Our western "Universal Spirit" is the same as that of the Indians, i.e. one for all. Therefore, it is up to the East to demonstrate it, and the West - to describe it, to each their own.

Keywords: subjectivity; solitude; western rationality; personality; self.

How to cite: Poroshenko, O. (2020). Subjectivity of Wersten Personality: Limits of Rationality. Postmodern Openings, 11(3), 318-331. https://doi.org/10.18662/po/11.3/217 


\section{Introduction}

If we don't go deep into scientific definitions and interpretations, then such words as "Self", "Subjectivity", "Internal World" appear to be the same. At least, they all stand for something inside the human, inside the intimate spiritual world that is hidden from curious eyes. This space, which is closed to others, is the most important and fragile "essence" of any human. Self is so important for us because we live our entire life with it. With whom, if not with ourselves, do we often talk, share our sadness and joy? With whom do we sing the popular melody from the yesterday's movie? Who do we trust our secrets? We are comfortable with "I" and "Myself"!

We talk to other individuals much less often. Even when we work with others on "cultural products" (Bourdieu, 1989), we are trying to express our own internal world more than anything else. If only we could cover the whole external world with our own blanket, then all the great dreams from "superman" (Nietzsche, 1999) to "ideal state" (Plato, 2003) would come true. "I" is so important for a western person, who was brought up in the culture of individualism, trust in himself, or at least in God's Son, that this person is ready to go to great lengths, to sacrifice his property, beliefs and even life for "I" and "own".

That all would be fine and even congruent with us, like in "macrocosm" if only that internal world was not so fragile. What terrible tragedies do we experience when confronted in minor internal conflicts with others arising from "misunderstanding", "non-inclusion" and "disrespect", not to mention life tragedies, such as "disregard", "solitude" and "selfdestruction". "To be or not to be?" that is the question the rational western "I" asks the self. There is only one answer to this question - "to be". And it is not just "to be" it is to exist: to act, to create, to move forward, in a word to be a Subject. Be proud of yourself, while pride is a sin! With each coming century we have to run faster, hassle more, think less and futurists scare us by the upcoming "shock", not only from the future, but also from the present.

Where can a poor human soul go, in which cavern of existence can it hide? To which island can he escape to meet carefree "Friday"? Globalization is coming from all sides, the world system does not need a person anymore, who has become an "observer", not part of anything and responsible for nothing. Systems are self-organizing, self-reproducing, in extreme cases they use "artificial intelligence". Where should homo sapiens go? We have been in "subconscious" before. We know our complexes from 
"Edipus" to "Little Red Riding Hood" (Fromm, 1976), we haven't lived but sublimate for nearly a century. We would devote ourselves to art, but we can't, there is no art anymore, only "five words in neon light".

So, western persons, you and I, face an insolvable contradiction: we want to create, as we are subjects, not animals, but postmodernists forbid us. Since it is forbidden to change the external world, there is only one choice: to refute the external world and turn your gaze into yourself. "Ontological turn" is our "response to Chamberlain" (idiom).

\section{Limits of western "I"}

So, what do we see in this "hole of existence"? Thanks to liberal democracy, we can see what we wish to see. Some of us see "reflection of existence" or "existence ", others see "fears" or even "nothing" (Sartre, 1992).

On the one hand, an endless variety of choices, for every taste and color, on the other hand, competition, laws of market. We can't live without market due to our "type of rationality".

Our philosophical spiritual leaders don't stay on "top" for long. In the 20th century alone we saw lots of transitions: they were marxists with neomarxists, freudists with lakanovists, fenomenologists with existentionalists, personalists with constuctivists; it is impossible to remember them all. What did they struggle for? Probably for the truth. Although no! There is no truth either (Baudrillard, 1994)!

Well done postmodernists! They left us without oxygen. Environmental disaster! "What to do?" Finally, this question became of interest not only to the "individual nation", but to the whole of Western civilization.

And western civilization got stuck on this question. Where are we going? What do we want? What are our supreme values? What is good and evil? There are only questions, no answers. Why? Maybe, there was no need to look for "Nothing" inside yourself, you had to see "Something"! Therefore, we discard the outdated question "what to do?" and raise a new question - "Who am I?" "Who am I?" sounds brave, courageous, heroic, who cares about postmodernists! If only we could find the answer to this question, "the Renaissance" would come again or even "Ancient Greece" and we would not be trapped in this untitled era. Modern was before, and Postmodern passed ...

We have no identity, in one word we are "divids", "flaneurs" (Benjamin, 2006). No mom, no dad, no king, no profit, no how, no idea. We 
have no ideals, no moral beliefs (fate), no trust, no ethical principles, we live in social and moral apathy, we are deserters. Whatever it is, just don't involve me, I am in virtual reality. Here I am comfortable, cool and anonymous. Here I can do anything. No punishment for any crime. This is my cave of existence, my underbelly. Want to join me? Make up a "nickname" and "let's chat", don't count on more.

We are "simulacra" on two legs, communicators. "The last thesis of kings" was "culture is communication". It means that we are two in one: determinant and determinate, the "communication tubes". That is who I am! I am a voice modem. I can talk, and the Existence talks through me. What if I "crash"? Will it be impossible to understand "Dasein"? Only one puzzle will not be solved or the mystery of the whole Existence? In this case, it is very responsible - I am the keeper of the "royal seal"of Existence. So, I am accountable as much as a Peer of England, I can't fail. If I screw up, then London's "Tower", "finita la comedia" guillotine or exile at a poorly heated provincial chicken farm.

Suppose, our "I" is really a "lumen", a transponder, a medium. Energy of existence is transferred by us, through us and via us, like electrical current over wires. This absolutely unique ontological ecstasy of my encounter with existence and the further objectification in mass media is called the "ontological turn" of the XXth century. That is why each of us has our own personal right to (know and declare) the Truth. No fools here, everyone is smart. Everyone "sings the song", expresses himself, changes images, denies authorities. All of us are equal participants on the market, comrades and buddies, brothers and sisters in the "United Existence" (like United Russia - a leading party).

In the process of accelerated truth mining, we don't have spare time neither to look around, nor study the mining methods of neighbors. Can their method be more effective than ours? Take the Indians. They must be very "dark", since they have been seeking "enlightenment" for ages. However, some very devoted and meticulous Indians managed to penetrate deep enough into the Atman's ontology and metaphysics. For the rest of their lives, the West must remember the names of Indian "cream of the crop" - Arad Kalam, Potthapad and Sachhack. Times that were dark for idols have passed! We have someone to follow and to whom to erect monuments. Now let us try to figure out the essence of the Hindu way of worship.

Compared to Indians, we, people of the West, have limited imagination. In our fantasies or scientific theories, if you wish, we cannot go beyond - over the limit: finite - infinite, knowable - unknowable, immanent 
- transcendent, profane - sacred, expressible - inexpressible, etc., etc. Thanks to "protestants" ethics" (Weber, 2001) or contrary to it, rational West arrived at its last harbour, which it named "Dasein" and that's it. The hole was made in Existence and the ship leaked. And weird enough, the more of existence flows in, the faster the ship sinks.

Can we plug that hole? Remember - disconnect that voice modem? Take the man down from the "top of the World"? Let him rest, feel like a speck of dust, a grain of sand, an insect, something a little less important than "superman", "king of nature" or «Subject». Indians and Chinese understood it long time ago and at least tried to live in harmony with nature, do not do harm to anyone and even value a cow above the man.

Saving the drowning is the work of the drowning. The West must dig deeper in its own cultural soil and find its "own" response, understand the situation, i.e. recognize the familiar. Forward to the past! Long live orthodox iciaxasm Jesuism and Muslim Sufism! Long live a spiritual soul and Christian prayers! This is our Western metaphysics. Of course, in some areas of the West, "God is dead" (Nietzsche, 2001) but as it often happens, the more time passes after funerals, the faster the bad is forgotten and only the good and the bright remain, which was associated with the deceased. So, going through the days of nihilism, communism and market capitalism, the West became nostalgic for the irrational, transcendental, emotional world of religious culture. On September 11, 2001 the West remembered its religious identity.

Who am I? I have faith does not matter in what, in gods, in communism in myself. Faith is given to a man only once and he needs to live with it, so that at the end it "would not hurt to think of the years spent without purpose." A man would give anything, to go beyond the limits of ordinary thoughts, to struggle his way to the Truth and develop his own individual soul to the heights of the universal. It is boring to be "limited", I want to be "unlimited". The Truth is above causes and consequences and it will set us free! Forget the "enlightened mind", long live "unreasonable faith". What can we lose, except the shackles of our thoughts? Let's take a chance. Maybe we will discover something else in our pockets? For example, “self', like Indians.

The one sitting inside us is "Someone", like a taken hostage princess, there is nobody to talk and it is impossible to get out because of rational fetters (not to be confused with captain Freud's "gin in the bottle"). First and foremost, "Someone" is the ontological basis of "my" individuality, "meeting point", which cannot be changed, with Existence. Secondly, 
"someone" is metaphysics of universal presence of above and beyond, the "assembly point", the workshop to repair "my" subjectivity.

If we freed our mind from pragmatic chains, we would clearly see that sociological problem of self-identification is more fundamental, it is a problem of self-justification of "my I", i.e. a problem of my personal anthropodicity. "Who is he?" is "his" problem, let "him" think of it. I will never understand "who" she/he is, if I don't understand "who" I am.

When we look deep inside our own "I", it is very difficult to focus and keep studying that "I". We are tempted to switch our focus and attention to the personal life of our neighbors or to the politics of the neighboring independent state. There are a lot of options, in spite of the fact that we hear quite often: "look at yourself", "and who are you?", "what are you", even "you are nothing". It's time to take offense and find a decent answer. Let's set our imagination free, maybe a scientific concept will come out?

Our internal world is very big, it is bigger than the external world, because we are able to "grasp", feel, see, touch, smell etc. the whole external world or what we mean by it. This world is "alien" for us, we are guests in it, just drop by to socialize. First, we are cautious in the world as with any stranger, and gradually become either friends or enemies. The closest friends of the external world are scientists, who know everything about it, "call it by the first name", fly to the Moon and touch stem cells with the forceps. And we'd better not argue with them. But there is nothing like home. Wherever we go, whatever we do, sooner or later we come back home, to self, except Heidegger, who "stuck" at a party and continues talking... Our "own" internal world is huge, infinite in comparison with the finite being of a separate human life. We will never know why it is so huge, who or what made it because "similar cannot be understood by similar". That is why, we cannot describe it as a bug under the microscope, and we need a different methodology, the methodology of an "internal observer". Mankind has invented several such methods, like meditation, intuition and techniques of "expanding consciousness". However, for us, representatives of Western culture, it is hard to adapt to them. Not every European wants to fall into a trans in traffic jams or take LSD for breakfast.

We need something rational and technologically sound. We are used to living according to the "idea", sample and model. We are the children of paternalist culture. Give us a theory and we will live according to it! Therefore, a western "internal observer" is a sober reflexing " $\mathrm{I}$ ", the subject of our subjectivity, and the object for it is not "external", but "internal" world and everything that is presented in it: Existence, God, Cosmos, 
Brahman etc. The external world is an objectivation of the internal one. For the external world the principle of reflection is replaced by the principle of interpretation. Today no representative of the "university public" will argue with this. There are a lot of objectifications of the internal world like multiple Atman modes. Objective modes of the human internal world are represented in all spheres of human activity: science, culture, art etc.

Consciousness, reason, instincts, existential feelings are only the constituent parts, "bundles and lines" of our subjectivity, our internal world. Why do they disagree with solipsists, if the "world is a complex of my feelings" (Berkeley, 2003), not of Aunt Kate's neighbours? This means that like "identity of existence and thought" or "preexistence of Dasein in the world", in the objects of subjectivity- God, Cosmos, Brahma there are reasons not only for their cognition but also for the existence of human subjectivity itself, even my own. The man can understand God, Cosmos, Brahma only within the framework of his own subjectivity, which is given to him ontologically and metaphysically. Understanding of the external world is secondary (forgive me esteemed scientists). That was declared by the ancients - "nosce te ipsum" of Socrates (Plato, 1992); in middle ages ("homo interior" (Saint Augustine, 1960) and the recent "life world" (Husserl, 1970) and "hermeneutic circle" (Gadamer, 1986). The question - What is the meaning of being-Dasein? Can be posed only if ontology does not turn into a doctrine of the totally closed existence of entity. A man must understand what he is inside from the very beginning, and this "beginning" lies deeper than his "ontology".

\section{Resposibility of western "I"}

A man has been called "an animal", "a rope", "a model”, “a nonspecified creature", but he still does not know who he is and where he came from. We offer our own version: a man is a "funnel", the wider part is inside, the narrower is outside. The man's will creates the direction of movement from inside out (e.g. from the sacred to the profane). Each of us gives out "the unique product" - our own personality by filtering the world through us. Thus, "I" creates itself, without exogenous help from other "I" s. Therefore, I have a responsibility, first of all, to myself and then to parents, homeland and law. Sounds egoistic? Rather egologic than egoistic! We can look at situations from the point of view of dialectics if I am responsible to myself, then I am free in relation to others, e.g. parents, homeland and law. The more responsibility for oneself the "I" takes on 
itself, the more social freedom it gains. "We are not slaves! Slaves are not us!"

A free person always looks aesthetic. He is courageous and energetic, handsome and charismatic. He is always surrounded by friends and fans, because, as we know, beauty attracts people. So to reach the perfect harmony, and therefore, to prevent conflicts with the outside world, a free hero can only open the veil over the tragic collisions of his inner world. The whole struggle - the pangs of choice and the passion of love are there. There he fights with the "demons" of his soul: prostrates himself before divine love, experiences existential feelings of despair and guilt. Everything inside, only a light "fleur" of these storms and tragedies can reach the "external observer". And this fleur only complements the aesthetic picture of the "hero of our time" with an ethical component. Beauty and Goodness are one!

It is necessary to note that the heights of contemporary romanticism can be reached only if the internal world is filled with tragic content. This is not as easy as it might seem at first glance. Much more often, we take our "internal moaning", with a vivid melodramatic effect, which we "promote" in the market of soap opera lovers for a genuine tragedy. Such attempts can be successful only on a segment of a "smoked cigarette, or in best case scenario, a drunk "sacred vessel".

The length of time equal to the duration of our sympathy is the time of the melodramatic impulse. When a lunch break is over, we have to go to the office or home to watch a show or see a hungry partner, which is the end of melodrama. The melodramatic impulse is our tears when we watch the parade of veterans on Red Square, our smiles when we meet with a ruddy toddler holding out a toy, our patriotic feelings when the country's anthem is played before the final match of the hockey team. Melodrama is our style of communication with others. Tragedy is our style of communication with ourselves.

The "absurdity of existence" (Camus, 1991) forever left us alone with its "expectations", "ideas" and "desires." A closed anthropological universe is the circle of totality, which like an excavator with a bucket, "raked" everything human from the universe. This pile, consisting of billions of combinations of events, emotions, experiences and "practices" is the authentic core of our individuality, "thing -in- itself" of subjectivity, human self.

So, if we remove the anthropological from the world, a void forms in it, a hole in the universe. Perhaps the "black holes" in space are the disappeared anthropological universes? Is this not what the "anthropic 
principle" says? Cosmos is cheese, but the question arises: what sort and type is it? To put it simply, are there many holes in it or just one? Rejecting anthropocentrism, one must remember that humans possess subjectivity and consequently, are subjects. The ontological property of subjectivity allows us to "collect", "subjectivize" everything that is captured by its "bucket".

\section{Solitude of western "I"}

"I myself" suggests not only heroism but also solitude. A man is alone from the beginning and forever. "I am alone" is an axiom and with a greater degree of certainty than "I think." When this obvious fact finally "reaches" a person, he even senses it physically. This hole (or sensation of a hole) is formed in the area of the solar plexus. Have you ever noticed? What happens to a person, when he thinks? Introspection - the eyes go glassy and the back of the head is itchy. But eyes can become glassy even in the absence of any thoughts! Solitude is an ontological state that "captures" a person completely: rationally, emotionally, socially, existentially and physically.

It is at this "moment of truth" that we realize and experience our self, our final and last "I". This does not happen to everyone. Some remain children, hoping to achieve the ecstasy of mutual dissolution in the social world until the end of their days, like a spoonful of sugar in hot tea. It does not matter whether it is a spoonful of sugar, salt or pepper. Hence the disappointment, resentment, scandals. "Do you respect me?" The problem is twofold: on the one hand, we want to "reach out" to the Other in order to understand or dominate, on the other hand, to be understood or "absorbed".

What do "I-You dialogues", "meeting events", "acts of communication" give to a person? Is it a constant search for oneself, even through the prism of love for the Other / neigbour? Solitude is "care" for oneself. They say that even suicides who jumped from the tenth floor instinctively try to cling to branches by flying past a tree. Will to live!

You meet the absolutely new Robinson! He does not want to rule over Nature and be the king of "Fridays" (Defoe version) or forget the rational censorship of consciousness releasing "libido" to bask in the sun (Turne, 2015). Our new Robinson is an authentic subject aware of his uniqueness recognizing himself and "his" always and everywhere: space, culture, society, God, another person. He does not care whether to return to "civilization" or stay in the wild. His "I" is always "above", "over", "meta", etc. Having realised and accepted our solitude, we become free. Only after going this way, you can allow yourself to "return" to the other "I" s, to 
society, because now we will not demand from our neighbor that, which he could never give away - his "I". The bottom line is that we need to respect and accept the "other" as other, different. Only then we can recognize and feel unity - we are both lonely. To know that you are not alone in your solitude, what could be more optimistic?

Having overcome the "love for one's neighbor", the desire to possess and be possessed, a person turns to another "I" in order to build communication on an essential ontological level. The search for "one's own" person (simply a friend) is determined by the knowledge obtained as a result of metaphysical knowledge of the transcendental by "my" subjectivity. In the Other, we are looking for the faces of "our" God, those "signs" that only my own "I" can recognize. This ontological communication allows one to "take off the table" the psychological and social features of another person. Individual originality will not allow unity to be formed. The special will not be universal.

The language of the ontological communication is the language of universals. Friendly communication is communication within the framework of a "highly contextual" culture, like the Chinese. Each concept has many meanings that are elusive to the outside observer, but "recognizable" by friends. Friendship is a game of the initiates: the Rosicrucians and the Templars - members of the hermeneutic circle. Remember how good and understandable it is to be silent with a close friend! The language of friendship is syncretic. Linguists believe that Russian has a lot of syncretic constructions, which is probably why Russians have special understanding of the word "friend".

To translate the language of metaphysics into forms of discursive practices is one of the "eternal" problems in Western culture. Since the days of the Silk Road, we began to import gunpowder, a compass, "reincarnation", etc. This path has been going on for centuries, bringing new curiosities into rational Western life: tamagotchi, nunchaku and yoga. However, the oriental metaphysics is impenetrable to the West.

Attempts to search for a "common" language have been made more than once. The entire "esoteric" line of European philosophy from Plato to Heidegger (2010) can be called the "technique of translating" oriental metaphysics into the language of European science, For instance, Heideggerian linguistic centaurus are still in use, for example, "co-existencehere-now-presence-in-itself-of that -Dasein". Or the "ontology of the meeting" is "here - now - for - me - you - us - him - her - them - this - that those - presence". That's how we Europeans through bamboozlement understand the metaphysics of the East! 
The attitude of the West towards metaphysical problems is specific, to put it simply, all the way rational relationship with metaphysics. We perceive "conceptually even such a phenomenon as death, " It seems that death is the limit / boundary of the being of a person which s/he cannot comprehend, overcome but even here the inquiring western mind does not want to give up its positions. They came up with the concept of "borderline situations" in which a person should be aware of his transient existence. In general, the topic of death is one of the most favorite and fashionable in Western humanistic thought of the last century. In the academic philosophy of the 20th century, it is expressed with enviable constancy in a series of consecutive murders. As the "enlightened mind" should, each murder is carefully thought out and takes its rightful place in the logic of successive deaths. First, they killed God. Then inspired by their own voluntarism, and after killing geniuses and revolutionaries, they "slaughtered" the Subject. And now, when "reflecting I" does not exist, the very same philosophy can "R.I.P." "Thank you, everybody! That was it!". Who is next? Agatha and Artur are gone. So, we can rely only on our own deduction skills.

Does this thanatological sequence sound familiar: death of a man/ body (sensation), - death of the subject (mind) - death of philosophy (selfreflection) - death of god (religion) - death of I (spirit). Yes, you are right! "Go, Hegel, go!" Took the hit. He deserves his title of the "last true philosopher." So, we know the victim, who is the murderer? The murderer is also known. It is "anonym", "flaneur", "simulacrum", "dividum", in one word, he is postmodernist. This cold rational killer methodically destroys all the nuts and bolts of phenomenological system of the great modernist. What are the motives?

One version is "deconstruction". Demolition is always fun! It is easier to build a monument to yourself on the ruins of old principles and past idols. Another version is esoteric "irony". Insiders information, as if for laughter, we will destroy everything classical, but in fact we will once again repeat the objective laws of existence. But this is a secret that we won't tell anyone. To support this deductive theory, it is worth mentioning that we are currently living in the era of subjectivity. The death of subjectivity or death of "the self" can be declared any minute.

Maybe we should try to prevent a crime? Ambush them? Put the decoy bait out? Let us stand with the whole world to defend our "internal world"? What does all this mean? Why, what, for whom? There is a small group of "aesthetes", who want "internal harmony", since they are tired of the spiritless pragmatism, formalism, consumerism and glamour, etc. Like "amateur archeologists" they are on an independent, illegitimate quest for 
their "I" alternately visiting either the temples of Science and Church, or the "Gardens of Epicurus". What does the future hold for them? To be "abandoned" in existence - they have already adapted to it, or thrown out from the "holiday of life" of modern society? Become marginals? Forget about creativity, "mind, honor and conscience"? They can't be silent in the era of information technology and mass communication. Therefore, calls for an "elite uprising", are getting louder, but let's not forget that in the classic version the elite was not globalized, but spiritual! Our western "Universal Spirit" is the same as that of the Indians, i.e. one for all. Therefore, it is up to the East to demonstrate it, and the West - to describe it, to each their own. And there will be "world peace", tolerance and homogeneity!

\section{Conclusions}

Today, the problem of developing alternative methods of constructing a new humanistic theory in the context of modern social realities is widely discussed in the world social sciences. All over the world, there is an active search for development of the contours of a research paradigm capable of entering into a dialogue with the established paradigms of Modernity and Postmodernity.

In the "West", attempts to solve a similar problem are the concepts of such contemporary philosophical movements as post-postmodernism (Kirby, 2009) and metamodernism (Vermeulen \& Van den Akker, 2010; Van den Akker et al., 2017; Epstein, 1995).

The relevance of the search for a new scientific language and research methods in humanistic theory is due to an obvious transformation of the picture of the social world order. This is due to the emergence of new global changes and conflicts over the past 30-40 years, the crisis of social structures and the active development of digital and network technologies, that is, the emergence of new social processes and practices.

Increasing psychological tension and anxiety, mental overload, change in subjective perception of reality, existential frustration, cognitive stratification of society, apathy and alienation of the individual represent a range of major consequences for each individual as a result of globalization changes. These consequences, which have a significant impact on the specifics of human being, should be discussed in a new way in modern Social Theory.

Therefore, the most promising area of research, from our point of view, today again becomes social anthropology and sociology of person, 
which set a new research task - to find the language of scientific description of the problem of uniqueness of personal being.

In conclusion, we would like to note that the problem of finding a scientific language to describe the uniqueness of ewstern personal being, the introduction of the philosophical category "unique" into the methodology of sociological and anthropological study is still little studied and requires further study.

\section{References}

Baudrillard, J. (1994). Simulacra and Simulation. University of Michigan Press Publ.

Benjamin, W. (2006). The writer of modern life: essays on Charles Baudelaire. Balknap Press of Havard University Publ.

Berkeley, G (2003). Treatise Concerning the Principles of Human Knowledge. Dover Publ.

Bourdieu, P. (1989). Genese historique d'une esthetique pure. Les cabiers du Musee national d'art moderne. Printemps.

Camus, A. (1991). The Myth Of Sisyphus And Other Essays. Vintage Publ.

Epstein, M. N. (1995). After the Future: The Paradoxes of Postmodernism \& Contemporary Russian Culture (Critical Perspectives on Modern Culture). University of Massachusetts Press.

Fromm, E. (1976). The Forgotten Language: An introduction to the Understanding of dreams, Fairy tails and Myths. Henry Holt \& Co Pbl.

Gadamer, H.-G. (1986). The relevance of the beautiful and other essays. Cambrige University Press.

Heidegger, M. (2010). Being and Time. State University of New York Press.

Husserl, E. (1970). The crisis of European sciences and transcendental phenomenology: an introduction to phenomenological philosophy. Northwestern University Press Publ.

Kirby, A. (2009). Digimodernism: How New Technologies Dismantle the Postmodern and Reconfigure Our Culture. Continuum Publishing Corporation.

Nietzsche, F. (1999). Thus Spake Zarathustra. Dover Publications Inc.

Nietzsche, F. (2001). The Gay Science. Cambridge University Press.

Plato. (1992). Protagoras. Hackett Publishing Co.

Plato. (2003). The Republic. Penguin classics.

Saint Augustine. (1960). Confessions. Image Books Ed Edition.

Sartre, J.-P. (1992). Being and Nothingness. Washington Square Press Publ.

Turne, M. (2015). Friday, Pacific or limb. Book on Demand Ltd. Publ.

Van den Akker, R., Gibbons, A., \& Vermeulen, T. (2017). Metamodernism: Historicity, Affect, and Depth after Postmodernism (Radical Cultural Studies). Rowman \& Littlefield Publishers. 
Vermeulen, T., \& Van den Akker, R. (2010). Notes on Metamodernism. Journal of Aesthetics \& Culture, 2(1). https://doi.org/10.3402/jac.v2i0.5677

Weber, M. (2001). The Protestant Ethic and the Spirit of Capitalism. Fitzroy Dearborn Publishers Publ. 